\title{
Participation in labour market programmes: a positive or negative signal of employability?
}

\author{
Accepted for Publication in Acta Sociologica
}

Authors: Flavia Fossati ${ }^{1}$, Fabienne Liechti ${ }^{2}$ and Anna Wilson ${ }^{3}$

\begin{abstract}
${ }^{1}$ Flavia Fossati, Inequality and Integration Department \& NCCR LIVES, University of Lausanne, Bâtiment IDHEAP, Rue de la Mouline 28, CH-1015 Lausanne, Email: flavia.fossati@unil.ch; +41216926910

${ }^{2}$ Fabienne Liechti, Social Policy Department, University of Lausanne, , Bâtiment IDHEAP, Rue de la Mouline 28, CH1015 Lausanne, Email: fabienne.liechti@unil.ch, +41216926891
\end{abstract}

${ }^{2}$ Anna Wilson, Social Policy Department, University of Lausanne,, Bâtiment IDHEAP, Rue de la Moulien 28; $\mathrm{CH}$ 1015 Lausanne, Email: anna.wilson@unil.ch, +41216926892

\begin{abstract}
Active labour market policies (ALMPS) are widely diffused measures aiming to re-integrate jobseekers into the labour market. Despite their crucial role in acting as gatekeepers to employment, the literature scarcely considers the employer's perspective of these measures. We analysed whether and how employers consider ALMP participation in the hiring process as a signal that helps explain the labour market outcomes of jobseekers. We developed a theoretical argument regarding how employers interpret ALMP participation and identify assumed agency, i.e., whether employers believe that the agency for initiating ALMP participation lies with the jobseeker (voluntary participation) or the job centre (mandatory participation), as a crucial factor determining whether their evaluation of ALMPs is positive or negative. To examine our expectations, we conducted qualitative interviews with employers hiring for low-skilled occupations in Switzerland and Sweden, representing two countries with comprehensive ALMP systems. As expected, the interpretation of ALMP programmes differs depending on the assumed agency. Employers who believe that participation is voluntary interpret participation as a signal of motivation; however, employers who believe that participation is mandatory interpret participation as a signal of lower productivity, which reduces the chances of a successful labour market access.
\end{abstract}

Keywords: Employers, interviews, labour market policy, recruitment, unemployment

Acknowledgements: We would like to thank, Giuliano Bonoli, Manuel Fischer and Gemma Scalise for their helpful comments and suggestions, as well as the editors and four anonymous reviewers, for their detailed and constructive feedback.

\section{Funding}

This work was supported by the NCCR on the move, Phase I, which is funded by the Swiss National Science Foundation [Project 7]. 


\section{Introduction}

Active labour market policies (ALMPs) are a key element of modern welfare states. These measures are meant to foster a successful labour market reintegration, particularly of vulnerable individuals. Primarily, these measures address the increasingly high levels of unemployment by adapting the skills of unemployed individuals to the changing needs of the fast-evolving labour market. ALMPs consist of a set of measures that focus foremost on the labour supply and include training, employment programmes (TEP) and wage subsidies (WS) (Bonoli, 2010; Filges et al., 2010 ).

Economic evaluations of these policies have mostly focused on their supply side effects. Only recently, there has been a growing interest in the involvement of employers in the implementation, provision, and evaluation of ALMPs (Bredgaard, 2017; Ingold and Stuart, 2015; Ingold and Valizade, 2017; van der Aa and van Berkel, 2014). The scarce existing evidence suggests that employers rely on information provided by ALMP participation when sorting applicants (Falk et al., 2005; Liechti et al. 2017; van Belle et al., 2018). However, the different effects that such measures have on employers' evaluation of candidates is unclear. While some measures seem to have a positive effect, other measures have no or even a negative effect on employers' hiring decisions and thus jobseekers' social and economic reintegration chances (Baert, 2016; Liechti et al., 2017). Overall, our knowledge regarding employers and whether and how they consider ALMPs is limited, even though such knowledge is essential to fully understand the effects of ALMPs and ensuring that ALMP participation is perceived as an asset rather than as a stigma.

We analyse two research questions; first, we inquire whether and why employers consider ALMPs for their hiring decisions and second, we analyse the consequences of employers' evaluations of ALMP participation in terms of jobseekers' employability. We focus on low- 
skilled service jobs because ALMPs primarily target low-skilled individuals, and these workers are most likely to be affected by unemployment because of the latest labour market transformations (e.g., automation and robotization). Low-skilled jobs are defined as occupations that do not require formal training and can be quickly learned on the job. Such occupations include sales staff in supermarkets, and cleaning and waiting staff at restaurants and bars.

It is important to note that in the service economy, employers hiring in the low-skilled sector seek two different types of qualities. In addition to the basic qualifications, employers increasingly demand soft skills, particularly the "right attitude" for front-line service work (Belt and Richardson, 2005; Nickson et al., 2012).

We develop a theoretical argument suggesting that ALMPs influence employers' hiring behaviour through two mechanisms. First, we argue that participation in ALMPs can directly increase the employability of a candidate (substantial effect) by adding relevant human capital or reducing wage costs (wage subsidies) (e.g., Bredgaard, 2015¹; Kluve, 2010). Second, ALMPs provide relevant signals regarding a candidate's soft skills, including attitude and motivation (signalling effect), and thus their productivity (Arrow, 1973; Phelps, 1972). In fact, the productivity of a candidate is oftentimes not directly observable; thus employers must rely on other information serving as a signal of productivity.

Our main theoretical and empirical contribution concerns the signalling effect of ALMPs and its effect on jobseekers' labour market integration, as one of the principal ways to guarantee a successful socio-economic integration in modern societies. We argue - and show - that whether employers consider participation in ALMPs as a positive or negative signal, and thus whether this intervention fosters or hampers labour market integration, depends on whom the 
employer attributes agency to initiate programme participation. In other words, the nature of the ALMP signal depends on whether employers believe that the main agency of programme participation was exerted by the state, job centre or caseworker and, thus, was the result of an institutional constraint or whether they believe that the unemployed individual actively participated in this decision. In the latter case, participation is likely to be interpreted as a positive signal (motivation). In contrast, when agency is assumed to lie with the caseworker, ALMP participation could entail a negative signalling effect (e.g., sanction). Importantly, for these effects to manifest, employers do not need to know how the system of ALMP allocation actually works, but their interpretation depends on their beliefs about how they assume the participants are allocated to ALMPs (Stryker, 1980). However, we acknowledge that ALMPs might also have substantive effect by relevant skills or reducing wage costs. Therefore, in the following we consider both, signalling and substantive effects.

For ALMPs to be effective and benefit their participants both the substantial and signalling effects of ALMPs need to be positive. From a sociological perspective such a positive effect is highly important because especially vulnerable individuals from lower social classes, including immigrants, perform low-skilled jobs. Accordingly, ensuring that ALMPs have a positive effect on their labour market (re-)integration chances is essential to facilitate their economic independence and their social mobility. However, previous research suggests that, in certain instances, ALMPs may have a negative effect on employment chances because they allow employers to identify a lack of relevant skills or use program participation to identify unproductive candidates (Liechti et al., 2017).

To test our theoretical argument, we carried out semi-structured interviews with employers in the retail and hotel sectors, which heavily rely on low-skilled labour, in Sweden and Switzerland. 
These countries are interesting cases because they invest extensively in ALMPs with a human capital focus and offer extensive (re-)training schemes (Bertozzi et al., 2008; Köhler et al., 2008).

\section{ALMPs and employability: developing the theoretical argument}

In this section, we develop our theoretical argument and formulate expectations regarding how and why employers consider individual ALMP participation when taking hiring decisions. Research on this topic is still scarce, however, the existing evidence indicates that employers are sceptical of ALMPs and that these policies exert a limited influence on employers' hiring behaviour. Bredgaart (2017) develops a typology of employers' engagement in ALMPs and empirically tests this typology with Danish employers. The results reveal that most employers are of the "dismissive" or "passive" type, accordingly that they do not actively participate in ALMPs and hold either negative (dismissive) or positive but passive attitudes, meaning that employers do not engage in or provide ALMPs. Ingold and Valizade (2017) conceptualise agencies delivering ALMPs as labour market intermediaries and test how ALMPs affect employers' hiring behaviour of members of disadvantaged groups. Their results demonstrate the ALMPs only have a limited influence on employers' hiring behaviour that is negligible compared to that of factors, such as firm size and employer selection criteria. Finally, Liechti et al. 2017 rely on a survey experiment simulating a hiring process and find that employers' interpretation of ALMP participation depends on the ALMP type and the candidates' employability. Overall, the results of previous studies suggest that employers consider ALMPS but are sceptical about their usefulness. Clearly, a gap in previous research is employers' reasoning regarding why they consider ALMPs for their hiring decisions and the types of measures they perceive as useful for different groups of applicants. 
Before formulating expectations regarding how specific ALMP measures influence hiring behaviour, we develop a general argument regarding why ALMPs should theoretically influence employers' hiring decisions.

Basically, ALMPs can affect employers' hiring behaviour for two reasons. First, ALMP measures can have a substantive effect ${ }^{2}$ on jobseekers' employability, such as by increasing the candidates' human capital or reducing wage costs (Bredgaard, 2015; Liechti et al., 2017). Second, participation in ALMPs can have a signalling effect. This effect occurs due to uncertainty regarding an applicant's productivity. We argue that employers should use participation in ALMPs as a signal conveying additional information, such as candidates' trainability and motivation to reduce uncertainty (Liechti et al., 2017). As forcefully argued by several scholars, in the low-skilled sector, employers are searching for candidates who are motivated and have a positive attitude towards work (Belt and Richardson, 2005; Nickson et al., 2012; Waldinger and Lichter, 2003). Thus, employers will try to extrapolate relevant information about candidates' attitude (also) based on their ALMP participation.

For ALMPs to be effective it is pivotal to be designed such that they convey positive signals. However, in practice, ALMPs can act as negative signals and, thus, result in unintended negative consequences (Burtless, 1985; Falk et al., 2005; van Belle et al., 2018). We argue that the nature of the signal depends on who the employers attribute the main agency of programme participation. Employers can attribute the decision to participate to either the jobseeker or to institutional actors. Thus, we expect that these signalling effects unfold independently of whether the assumption about how the ALMP system works - and therefore who has the agency - is correct or incorrect. It is employers' beliefs that affect their behaviour (Stryker, 1980). 
ALMP participation serves as a positive signal when employers believe that the main agency about the decision to participate lies with the jobseeker. When employers believe that the unemployed asked to be assigned to an ALMP measure, this would be an excellent way to detect their motivation (positive signal). In such cases, programme participation should signal a positive work attitude and the willingness to exert all effort to find employment. The completion of a more demanding measure might also convey a certain level of cognitive capabilities (Liechti et al., 2017).

However, employers can also attribute the main agency of programme participation to institutional constraints. When ALMP participation is perceived as mandatory or imposed by the caseworker, the positive signalling value of the programme is lost. Depending on the programme, participation then reveals a lack of relevant skills or problematic behaviour. At best, participation is no longer meaningful because assignment to a measure is assumed to occur automatically after a certain period of unemployment.

The expectation is that the substantive and especially the signalling effect play out differently for different programme types. In the following, we focus on the three most common ALMP interventions, namely, training, TEPs, and WS (Martin and Grubb, 2001).

In terms of signalling effects, participation in training programmes can signal a jobseeker's motivation to update relevant skills, or it can signal adequate cognitive capabilities (PES background interviews ${ }^{3}$ ). However, participating in a training programme can also reveal a lack of skills (Falk et al., 2005) and, therefore, entail a negative signalling effect. In fact, employers who believe that a jobseeker was assigned to a specific programme by a caseworker interpret this assignment as an assessment of skill deficits. In terms of substantial effects, training programmes are implemented to close gaps in relevant skills. Thus, employers should value 
training-based ALMPs because they increase human capital and, in turn, the expected productivity of candidates (Bredgaard, 2015; Kluve, 2010: 905; Liechti et al., 2017). However, we expect training programmes to have a substantive positive effect mostly when they teach specific skills directly relevant to a job or a particular employer rather than some general skill.

Participation in TEPs might be especially valued in the low-skilled labour market segment when employers assume voluntary participation as this signals the willingness to engage in unrewarding and repetitive activities that are typical for these occupations. Often, caseworkers use TEPs as a sanctioning device when clients do not comply with job search requirements (PES Interview 2; Auer and Fossati, 2019; Duell et al., 2010; Filges and Hansen, 2017). Consequently, employers who believe that TEPs are assigned to sanction recalcitrant jobseekers use participation to identify unproductive candidates. Finally, TEPs should not have a substantial positive effect because the setup of these measures barely increases human capital of participants (Gerfin and Lechner, 2002). Tellingly, these strategies are also referred to as "parking strategies" (Van Berkel et al., 2007). However, these programmes can serve as frameworks to structure the jobseeker's day and provide networking opportunities (Auer and Fossati, 2019; Bonoli, 2013; Duell et al., 2009).

Concerning WS, we do not expect a positive signalling effect related to a jobseeker's agency since asking for a WS does not reveal any information about a candidate's motivation or ability. However, the signalling value of WS can be negative because it may suggest that the ability of the candidate is judged below average by the caseworker (Liechti et al., 2017), allowing employers to identify unproductive candidates (Beart, 2016; Burtless, 1985). However, by reducing the monetary consequences of "riskier" hiring behaviour, WS should have a straightforward positive substantive effect (Bredgaard, 2015; Kluve, 2010). 
In summary, ALMPs can have both substantive and signalling effects. Concerning the signalling effects, which are our focus, we expect that the crucial difference between situations in which employers perceive ALMPs as a signal of motivation and instances in which they use ALMPs to avoid candidates depends on their assumption regarding who has the agency regarding ALMP participation. If employers perceive participation as an active decision by the jobseeker, we expect that any ALMPs are assets for jobseekers in the low-skilled labour market. In contrast, if the agency is assumed to lie with the caseworker, ALMPs participation reveals shortcomings or behavioural problems. Finally, if employers assume that ALMPs are assigned automatically, ALMP participation should not carry a signal.

\section{Case selection}

We conducted interviews with employers in Switzerland and Sweden, which provide good cases for analysing ALMPs because their PES offer extensive counselling services and an encompassing set of ALMPs to re-integrate unemployed into the labour market. In both countries, human capital enhancement is the core pillar and substantive investment is dedicated to these measures (Sweden and Switzerland invest $0.15 \%$ and $0.18 \%$ of the GDP, respectively, in training measures, Bertozzi et al., 2008; Köhler et al., 2008; Bernhard et al., 2019; OECD, 2017). Furthermore, the PES closely monitors job search progress and has strict sanctioning schemes to punish non-compliance. (Duell et al., 2010; Köhler et al., 2008; Sianesi, 2008: 372).

Additionally, the economic conditions are comparable. Unemployment is low, and unemployment provision is extensive for both passive and active schemes (Esping-Andersen, 1990; Bernhard et al., 2019). Furthermore, Sweden and Switzerland have a skill system biased 
towards specific skills and are characterised by a wage bargaining system that is coordinated at the industry level (Estevez-Abe et al., 2001).

However, there are also some differences. Sweden has a long tradition of ALMPs, which emerged in the 1940s, and played a pioneering role in activation policies (Bonoli, 2013; Köhler et al., 2008; Swenson, 2002). In Switzerland, these policies were adapted only in the 1990s as a reaction to the rapidly deteriorating labour market (Bertozzi et al., 2008). The extent to which the unemployed resort to the PES in Sweden is higher than that in Switzerland (Köhler et al., 2008; OECD, 2017). In the former, $81 \%$ of jobseekers contact the PES to find work, whereas in the latter, only approximately 52\% contact the PES (OECD, 2015: 165). Similarly, participation in ALMP programmes is very common in Sweden. For instance, during the period 2004-2015, between 3.0 and $5.22 \%$ of the total labour force participated in an ALMP. In contrast, in Switzerland participation varied between 1.0 and $1.6 \%$ of the total labour force (Duell et al., 2010; Köhler et al., 2008; OECD, 2017).

Our case selection was guided by the intention to obtain a reliable assessment of how employers perceive ALMPs. Accordingly, it is important to choose countries where these instruments are well developed and widely used. We do not expect differences in how specific types of ALMPs influence employers across different settings; rather, we expect employers' hiring preferences to be influenced by an economic logic that is likely to be similar across modern labour markets. Thus, we do not expect employers in the same sectors to value specific signals differently. However, to ensure that this assumption is true within the sample of countries with comprehensive ALMPs, we chose two cases that some extent differ in terms of their welfare state traditions. This strategy allows to draw conclusions that are more 
generalizable than insights that rely on a single case and, thus, could be strongly influenced by idiosyncratic institutional features (Gesthuizen and Sheepers, 2010).

\section{Data and methods}

To understand the meaning employers attach to ALMPs, we conducted semi-structured interviews with employers in the hotel and retail sectors. We asked questions about desirable qualities in candidates, the employers' hiring strategies and their perception of candidates. The interviews focused on the employers' view of the three most common ALMP interventions, i.e., training courses, TEPs, and WS. We chose these ALMPs because they are easily observable by employers, while other measures, such as counselling and monetary sanctions, are unlikely to affect employers' hiring behaviour because employers are unable to observe these measures.

The employers were sampled according to the size of their establishment (small and large firms) by ensuring that the establishments had a person specialised in hiring and that the site is easily accessible. These criteria were chosen to ensure that the interviewed employers all had hiring experience and that their hiring procedure is representative for a non-negligible portion of jobseekers. Within these criteria, the employers were chosen based on convenience. Since our sample covered large retail chains, which are present throughout the country, we decided to interview a smaller sample of retail establishments. In these cases, we interviewed HRresponsible from middle-management to ensure the capture of the company's overall recruitment strategy.

We conducted the interviews between September 2016 and March 2018 in Sweden (Malmö/Örebro) and Switzerland (Bern/Zürich/Basel). The interviews were recorded (except for two cases in which informed consent was denied) and transcribed in the original language. 
We carried out 17 interviews in Switzerland and 14 interviews in Sweden. Regarding our respondents, 14 respondents were male, and 17 respondents were female; 24 interviews were carried out in hotels, and the remaining interviews in retail enterprises. The experience of the interviewees varied from less than 5 years to over 10 years, and the interviewees performed different functions: 12 respondents were involved in the hiring process as HR professionals, 7 respondents were line managers, and 12 respondents held management positions or were the owners of the hotel (Table A1 in the appendix).

We developed a coding scheme (Table 1) to classify the employers' statements into different categories. The coding procedure was theory driven but inductively refined such that we capture the reasoning employers gave for (not) considering the three main ALMP types (training, TEP and WS) in their hiring process.

\begin{tabular}{|c|c|}
\hline Step 1: & Thematic Fields \\
\hline \multicolumn{2}{|c|}{ Awareness of ALMPS } \\
\hline & Is aware of ALMPS \\
\hline & Is not aware of ALMPs \\
\hline \multicolumn{2}{|c|}{ Type of programme } \\
\hline & Training (further vocational training or specific courses) \\
\hline & Temporary employment programmes \\
\hline & Wage subsidy \\
\hline Step 2: & Reasoning \\
\hline \multirow{2}{*}{\multicolumn{2}{|c|}{$\begin{array}{l}\text { Reasoning for considering } \\
\text { ALMPs }\end{array}$}} \\
\hline & \\
\hline \multirow{3}{*}{\multicolumn{2}{|c|}{$\begin{array}{l}\text { Substantive effect: } \\
\quad \text { - } \quad \text { Human capital } \\
-\quad \text { Incentives to hire (wage subsidy) }\end{array}$}} \\
\hline & \\
\hline & \\
\hline \multicolumn{2}{|r|}{ Screening device: } \\
\hline & - Positive signal \\
\hline & - Negative signal \\
\hline & - Neutral (No signal) \\
\hline
\end{tabular}


As outlined in the theory section, these reasons could either be classified as substantive effects, or positive or negative signalling effects.

Whenever employers were unaware of ALMPs, their answers concerning how they evaluate candidates who participate in such measures was still coded because, as explained in the theory section, it is not necessary to fully know the ALMP system; in contrast, we expect that beliefs of how the system works influence employers' behaviour. The coding scheme was validated several times by choosing some interviews that were (re-)coded by all authors. This iterative procedure allowed for adjusting unclear codes or discussing difficulties in the categorisation of specific interview parts (Charmaz, 2001; Yin, 2003). After this validation process, each author was responsible for coding several interviews. First, the relevant passages were assigned to thematic fields, i.e., awareness of ALMPs and program type. Second, within each thematic group, the statements ${ }^{5}$ were assigned to different reasoning regarding how ALMP participation was interpreted.

\section{Results}

Whether and how employers interpret ALMP participation

We now analyse employers' perception of different ALMPs and whether this perception depends on the assumed agency of ALMP participation.

In general, our findings show that the employers in both countries are not very familiar with ALMPs and their allocation processes (cf., Ingold and Stuart, 2015; Ingold and Valiade, 2017). Nevertheless, employers consider ALMP participation when hiring. This result shows that it is not necessary to know how the system works to interpret information; instead, the employers attempt to make sense of any information provided to them and use such information to 
improve their assessment of the candidate. This finding is in line with those reported in other studies in which employers are shown to pay attention to different types of information, including hobbies, attractiveness, social background, etc. (e.g., Rivera 2011; Rooth, 2012). As expected, the results further show that there are no systematic differences between employers Switzerland and Sweden regarding their interpretation or use of ALMPs.

Overall, only a minority of employers think that ALMP participation is altogether irrelevant. Such employers draw a distinction between a person and his/her skills and the unemployment experience. Consequently, these employers do not consider a person's ALMP experience when evaluating the candidate; therefore, ALMP participation results in a neutral signal, which is exemplified in the following statement:

If you have these skills [IT skills for a position as receptionist], have been unemployed, have been in these temporary employment measures and then look for a reception job with us, no problem. It doesn't matter what they have done. (Hotel5 SWE)

Employers who instead consider ALMPs when hiring can be divided into two groups. According to our theoretical argument, some employers believe that ALMPs are mandatory either by law or are imposed by a caseworker possibly as a sanctioning tool. Such employers tend to only slightly consider this information (neutral signal). This way of interpreting ALMPs is nicely summarised by a respondent:

It is not the person per se who can be held responsible for the fact that they have gone through these measures. They have to do it; they have to do something according to the PES. Those are the rules; so, I don't think anything of that. Their experience with these programmes doesn't signal anything in particular. (Hotel5SWE) 
A substantial number of employers believed that ALMP participation is voluntary and, thus, at least partly actively initiated by the unemployed person. In instances in which ALMP participation is assumed to reflect an individual decision by an unemployed individual, ALMP participation is considered a positive signal and is associated with a particularly high motivation to work.

This shows me that there is the will to work. I think this is an important sign. (Hotel3CH)

That's great because I think it is better to do something like that [an ALMP] than sit at home and do nothing. (Hotel8SWE)

These findings are consistent with our expectation that depending on the attribution of agency, the signals of specific programmes may be altered.

Finally, we find that a minority of employers interpreted programme participation as a negative signal of behavioural or other shortcomings.

Whether and how employers considered ALMPs in their recruitment decisions did not seem to vary systematically among different types of employers. The only difference emerging was that larger companies with a more professionalized HR management seemed to be more likely to hire from disadvantage groups, such as migrants or long-term unemployed, and were more willing to offer training opportunities to this population. Often, employers highlight their social responsibility as a reason for giving weaker candidates a job opportunity. Smaller establishments could hardly afford the risk of hiring the wrong person as a hotel manager suggests:

So far, this has not happened because we have too little support capacities. (Hotel7CH) 
If the employers were willing to hire jobseekers, they often mentioned that only the financial support of a WS would allow them to give a potentially "problematic" candidate an opportunity as exemplified by the following quote:

So, [a WS] would certainly give me an incentive to try someone you wouldn't try otherwise. Someone who feels like I don't know exactly, but then you would say "ok, try it". (Hotel3CH)

Employers' interpretation of ALMPs and its effect on applicants' employability

Let us now discuss how employers evaluate the substantive and signalling value of different ALMP programmes. In Table 2, we summarise the employers' interpretations based on the categories developed in the theoretical argument and discuss these interpretations . 


\begin{tabular}{|c|c|}
\hline \multicolumn{2}{|l|}{ Training } \\
\hline $\begin{array}{l}\text { Substantive } \\
\text { effect }\end{array}$ & $\begin{array}{l}\text { - } \quad \text { Basic training is not enough } \\
\text { - Training must match the job } \\
\text { - Ideal to provide migrants relevant skills } \\
\text { - Valued when provides skill certification }\end{array}$ \\
\hline Signalling effect & - Basic training: Reveals a lack of competences (negative) \\
\hline \multicolumn{2}{|l|}{ Wage Subsidy } \\
\hline $\begin{array}{l}\text { Substantive } \\
\text { effect }\end{array}$ & $\begin{array}{l}\text { - Allows for a testing period } \\
\text { - Does not have time to supervise (low-productivity) candidates } \\
\text { - Important to not exploit the person and hire him/her after the } \\
\text { subsidies expire }\end{array}$ \\
\hline Signalling effect & - Reveals a lack of productivity \\
\hline \multicolumn{2}{|l|}{ TEP } \\
\hline $\begin{array}{l}\text { Substantive } \\
\text { effect }\end{array}$ & $\begin{array}{l}\text { - It is ideal that a person does something and has a daily structure } \\
\text { (TEP) } \\
\text { - TEPs do not correspond to reality and generate expectations that } \\
\text { are too high }\end{array}$ \\
\hline Signalling effect & $\begin{array}{l}\text { - Shows that someone is motivated and really wants to work } \\
\text { - Reveals problems: What is the reason for someone to need a TEP? }\end{array}$ \\
\hline Neutral & - It is better than nothing (TEP) \\
\hline
\end{tabular}

Training Training programmes can have a positive substantive effect on the jobseeker's human capital endowment by providing skills that are lacking (Category "human capital", Table 2). However, the interviews reveal that often, training is not perceived to teach the skills needed for the job. Some employers doubt that training is useful either because these skills are soon forgotten or because these measures do not target the occupation for which a candidate is applying. Two hotel managers explain that training is relevant only if targeted to their business needs as follows:

I mean, it's not a bad thing. But, then, I don't know if that certain course can help. Let's say, someone took a course in cooking for two years, comes here and asks for a job. It's 
more likely that we take that person than someone who has not. So, it's not a bad thing. But [it needs to be] close to our business. (Hotel6SWE)

The benefit of it is limited because the computer course they had to do would be our booking system and this cannot be offered by the PES. (Hotel6CH)

This finding suggests that training programmes are not used to assess the level of the trainability of a candidate probably because these occupations require only basic or very specialized skills.

The following citation supports the expectation that the negative signalling effect of training programmes, which reveal a lack of relevant skills, is likely to manifest only when hiring for midto high-skilled positions.

But, if the vice director did a computer course, he would not be suitable for me. Or even a receptionist; here, you expect that the candidate already has this knowledge. (Hotel3CH)

The situation differs for candidates with a migration background. For these jobseekers, most programmes seem to be perceived as having a positive substantive effect. Employers appreciate the effort to learn the language or acquire specific skills:

We have people in the kitchen who also come from that Snabbsparet [a programme called "Fast track to employment"]. [...] Some of them are just new in Sweden; they come from Syria, Afghanistan [...]. The main thing is that their Swedish is not very good; so, that's what they help them with. (Hotel7SWE)

Such programmes are judged positively by nearly all respondents because they match the tasks carried out on the job and provide relevant experience. 
Yes, it [a training programme] is a plus because the candidate was already in the working structure, already knows what to expect, has already heard about hygiene regulations. (Hotel5CH)

Interestingly, some respondents in Switzerland stated that they only consider training programmes that are offered in the private market and provide an official diploma. This finding reflects the importance of skills certification in the Swiss labour market (Rosenbaum, 2001). Although certification might matter less for low-skilled positions, documentation of formal qualification might still be important as suggested by the following quote:

If the PES would say we have paid a "SIZ" [specific computer course] or a "BEC" [language diploma] or an "Alliance Français" [language diploma] or something like that, then this has more weight for me. (Retail16CH).

Overall, our findings regarding training suggest that these programmes are valued only if they are perceived to provide knowledge that is directly relevant to the job and are mostly interpreted according to their substantial effect. This finding especially applies to migrants because for these jobseekers, the training programmes might compensate for the disadvantage that they experience due to discrimination (Auer and Fossati, 2019). Our findings show that in the low-skilled sector, training programme participation is almost never interpreted as a positive signal of motivation and hardly ever as a negative signal of a lack of skills.

Wage subsidies Subsidies reduce wage costs; therefore, they should have a positive substantive effect. However, as shown in previous research, WS may also be used by employers to screen unproductive candidates (Baert, 2016; Liechti et al., 2017). The interviews provide more 
evidence supporting the negative signalling effect than a positive substantive effect, and many respondents believe that applicants eligible for WS are less employable.

Those employers who would consider hiring candidates eligible for a WS stress the importance of not exploiting the applicants or the system and employ these candidates only when after the subsidy has expired; then, a job can be offered:

It is important not to exploit someone but that there is a real hiring prospect later, that there is a supervisor who can work the person in [and] show her everything. (Retail15CH)

In most cases, the respondents said that they use WS as a testing period to determine whether a candidate integrates well into the team and is friendly with customers. Thus, this measure provides a way to "try" candidates without financial risk as follows:

For me, it would be an incentive to try someone whom you would otherwise not hire. Someone, where you have the feeling that you are not so sure, but then, [with the subsidy] you would say, "Okay, I'll try." You cannot lose much. (Hotel3CH)

However, most respondents were sceptical and stated that a WS would not incentivise them to hire someone. In fact, they associated WS with lower productivity and higher costs of supervision, for which they do not have the necessary resources.

So, having someone who is like free or who has financial help or someone who doesn't know how to work, who is lazy, then I prefer to have someone regular. Because it is just a waste of time. If we have a person for free [on WS] who doesn't do anything, we need to pay another person to do the job. (Hotel1SWE)

Other employers stated that they would pay attention to possible behavioural problems of a candidate entitled to a subsidy and that they would perform a background check. This result is 
consistent with the findings reported by Baert (2016) and Liechti et al. (2017) who show that employers use WS as a screening tool to identify unproductive candidates.

Temporary employment programmes Based on the evaluation research on TEPs, we assumed that participation in TEPs does not have a substantial effect. In fact, we found that employers do not consider these measures in terms of substantive but primarily in terms of signalling effects. The results show that employers interpret TEPs participation either as signals for the acceptance of unrewarding work or of high motivation to re-integrate into the labour market. Alternatively, we expected and found that TEPs are used to screen unproductive candidates, suggesting that participation in such programmes can have a negative signalling effect.

Most respondents said that TEP participation was better than nothing and that it might be a way of providing jobseekers with a daily structure and showing their willingness to work. A recruiter in Sweden stated the following:

I would say: "Okay, but at least this person has done something, not just being unemployed and collecting money. They probably want to do something and want to feel useful, and they have a drive" - that's what I would like to look into. (Hotel7SWE)

Approximately one-fourth of the respondents use programme participation to detect motivation and a service-oriented attitude and said that following a TEP shows that the candidate is motivated to carry out basic monotonous work as follows:

I have already said that with the breakfast buffet, that is more like basic work, and when someone keeps up with doing that [participating in a TEP] for five months, he will also keep up with the breakfast buffet even though it is kind of monotonous work. (Hotel3CH) 
Clearly, however, the respondents' interpretation of ALMPs is influenced by their understanding of how TEPs are assigned to the unemployed. The respondents who mentioned positive signalling effects often attributed agency to the unemployed individual. These employers judged programme participation as showing the jobseekers' willingness to reintegrate into the labour market, revealing that they are unfamiliar with the working of the PES and programme allocation, which can be enforced by caseworkers as a sanctioning tool (Category "negative signal" in Table 2).

The respondents who were aware of the allocation process were more critical of TEPs as follows:

Yes, I mean the question always arising is why? Why does a person reach that point [of being assigned to a TEP]? (Retail10CH)

As expected, participating in a less rewarding ALMP can be interpreted in different ways. On the one hand, if agency is attributed to the jobseeker, it can signal willingness to work. On the other hand, if agency is attributed to the caseworker, it might be interpreted as an indication of behavioural or other problems and, therefore, have a negative signalling effect. This may explain why some evaluations of TEPs find that this type of measures has a negative effect (Card et al., 2010; Kluve, 2010). However, most employers hiring in the low-skill job market were either neutral regarding TEPs or interpreted participation as a signal of high motivation.

\section{Discussion}

Our findings suggest that employers in Switzerland and Sweden are not very familiar with ALMPs and their implementation. Most employers were unaware of whether unemployed individuals could request participation in an ALMP or whether caseworkers assigned these 
measures (also as punishment). However, we found that precisely the belief about whom had the agency in initiating program participation had a deep impact on how ALMP-related signals are interpreted by employers. To interpret ALMP participation, however, it is not necessary to know how the system works it is sufficient to hold beliefs regarding how the system works and what the content of the measures is.

In general, the findings regarding employers' interpretation of ALMPs in their hiring decisions are at best modestly positive. Employers' interpretation of ALMP participation seems to depend on the general distance to the labour market of the candidate. For candidates that are perceived as having a harder time finding a job, ALMP participation is evaluated more positively than for stronger candidates (Liechti et al., 2017). Unsurprisingly, employers value training programmes for migrants the most because these programmes directly prepare migrants for basic work in the low-skill sector of the labour market (substantive effect). For other candidates, the use of training programmes is questioned. Thus, it is difficult for ALMP providers to adapt to offer general courses that are relevant to a larger group of jobseekers if employers demand very specific skill requirements.

The skill level of the job also has consequences on employers' judgement of ALMP participation. Employers tend to interpret TEPs as positive signals for low-skilled tasks that do not require formal qualifications, such as room cleaning or working in a hotel kitchen. However, employers evaluate the measures positively only when they assume that individuals decided to participate on a voluntary basis because this participation suggests the "right work attitude". Otherwise, employers use programme participation to screen unproductive candidates.

Therefore, our research questions the utility of TEPs from the employer perspective not only because they are not perceived as providing a substantial added value but also because they 
can be interpreted as a negative signal. Finally, whether ALMP training is more useful in higherskilled occupations remains an open question. However, our argument suggests that employers hiring for skilled jobs may interpret course participation as a lack of human capital rather than focusing on the possible substantive advantages linked to increasing human capital likely because training is often not targeted to specific occupations.

\section{Conclusion}

Employers in the low-skilled sector are increasingly likely to be confronted with jobseekers who participated in ALMP measures because these programmes have been widely implemented in OECD countries to address the mismatch of labour supply and demand (Bonoli, 2013). While the aim of these interventions should be to help re-integrate the unemployed into the labour market and thus prevent negative socio-economic outcomes, especially for vulnerable jobseekers, the effectiveness of these measures is controversial (Card et al., 2010; Kluve, 2010). The suspicion is that some ALMPs have unintended negative consequences, including a stigma effect that may be engendered by negative signalling effects, that prevent the unemployed from successfully re-accessing the labour market.

We argued that to better understand why some programmes are more effective than others in positive social outcomes, it is important to consider the employers' perspective and analyse both the substantive and the signalling value of these measures. In particular, we theorised that ALMPs are successful only if employers consider them an asset in a resume and that this is most likely the case if employers perceive the jobseeker to have the main agency in the decision to participate in such a measure (positive signalling effect) or if there are non-trivial substantive effects (monetary benefit). 
Our results reveal that indeed employers' interpretation of ALMPs varies with the assumed attribution of agency. Specifically, TEPs have a positive signalling effect only when the agency is attributed to the jobseeker and not to the caseworker; otherwise, these measures are used to identify weak candidates.

Future research should inquire how other characteristics, such as the length of unemployment, age, gender and other factors known to influence labour market outcomes, intervene with employers' interpretation of ALMP participation and thus affect jobseekers' socioeconomic outcomes. As especially low-skilled workers are affected by ALMPs, due to their higher risk and duration of unemployment, it is important to create measures that are helpful for these individuals and do not further penalize them in their labour market integration.

The fact that the attributed agency influences how these measures are perceived by employers poses a dilemma for public policy: on the one hand, increasing employers' engagement in such measures could be helpful in improving the link to the labour market (van der Aa and van Berkel, 2014); on the other hand, a deeper knowledge of these measures might incline employers to use programme participation to screen unproductive candidates.

Policy makers are undoubtedly confronted with a dilemma that is difficult to solve. However, given the amount of resources devoted to these programmes, a closer examination of the reasons why some programmes may develop unintended consequences seems crucial to address their shortcomings. In fact, in the foreseeable future, atypical work biographies, along with frequent unemployment spells and ALMP participation, will become even more common than they are currently. 


\section{Endnotes}

1 Bredgaard (2015: 439) defines this as the "participation effect".

2 By effect we mean that a certain ALMP measure can affect employers' hiring behaviour. However, our aim is not to measure the size of this effect.

3 We conducted interviews with PES employees to provide useful background for our study. These PES employees, confirm that TEP programmes are considered as ways to occupy the day of the unemployed rather than provide meaningful training.

4 The PES employees from the PES background interviews also told us that TEPs are used as control functions.

5 We define statements as units of sentences where the interviewees provided an argument or a point. When a statement refers to two analytical categories, we code it twice. 


\section{Literature}

Arrow K (1973) The Theory of Discrimination. In: Ashenfelder O and Rees A (eds) Discrimination in Labour Markets. Princeton University Press, Princeton.

Auer D and Fossati F (2019) Compensation or competition: Bias in immigrants' access to active labour market measures. Social Policy \& Administration 12(6). DOI: 10.1111/spol.12532.

Baert S (2016) Wage Subsidies and Hiring Chances for the Disabled: Some Causal Evidence. European Journal of Health Economics 17(1): 71-86.

Belt V and Richardson R (2005) Social Labour, Employability and Social Exclusion: Pre-Employment Training for Call Centre Work. Urban Studies 42(2): 257-270.

Bertozzi F, Bonoli G and Ross F (2008) The Swiss Road to Activation: Legal Aspects, Implementation and Outcomes. In Eichhorst W, Kaufmann O, and Konle-Seidl R (eds) Bringing the Jobless into Work? Experiences with Activation Schemes in Europe and the US. Berlin: Springer Verlag, pp. 121-155.

Bernhard L, Fossati F, Hänggli D, and Kriesi H (eds) (2019) Debating unemployment policy. Political communication and the labour market in Western Europe. Cambridge: Cambridge University Press.

Bonoli G (2013) The Origin of Active Social Policy: Labour Market and Childcare Policies in a Comparative Perspective. Oxford: Oxford University Press.

Bonoli G (2010) The Political Economy of Active Labor-Market Policy. Politics \& Society 38(4): 435-457.

Bredgaard T (2017) Employers and Active Labour Market Policies: Typologies and Evidence. Social Policy and Society 17(3): 365-377.

Bredgaard T (2015) Evaluating what works for whom in active labour market policies. European Journal of Social Security 17 (4): 436-452.

Burtless G (1985) Are Targeted Wage Subsidies Harmful? Evidence from a Wage Voucher Experiment. Industrial and Labor Relations Review 39(1): 105-114. 
Card D, Kluve J and Weber A (2010) Active Labor Market Policy Evaluations: A Meta-Analysis. NBER Working Paper No. 16173.

Charmaz K (2001) Grounded Theory. In: Emerson R (ed) Contemporary Field Research: Perspectives and Formulations. Waveland: Prospect Heights, pp. 335-352.

Duell N, Tergeist P, Bazant U and Cimper S (2010) Activation Policies in Switzerland. OECD Social, Employment and Migration Working Papers No. 112.

Esping-Andersen G (1990) Three worlds of welfare state capitalism. Princeton University Press, Princeton.

Estevez-Abe M, Iversen T and Soskice D (2001) Social Protection and the Formation of SKills: A Reinterpretation of the Welfare State. In: Hall PA and Soskice D (eds) Varieties of Capitalism. The Institutional Foundations of Comparative Advantage. Oxford: Oxford University Press, pp. 145183.

Falk A, Lalive R and Zweimüller J (2005) The Success of Job Applications: A New Approach to Program Evaluation. Labour Economics 12(6): 739-748.

Filges T, Geerdsen LP, Smedslund G, Klint Jørgensen AM and Geerdsen LP (2010) Active Labor Market Programme Participation for Unemployment Insurance Recipients. Campbell Systematic Reviews $1-342$

Filges T and Hansen AT (2017) The threat effect of active labour market programs. Journal of Economic Surveys 31(1): 58-78.

Gesthuizen, M and Scheepers, P (2010) Economic Vulnerability among Low-Educated Europeans: Resource, Composition, Labour Market and Welfare State Influences. Acta Sociologica 53(3): 247-267.

Ingold J and Stuart M (2015) The Demand-Side of Active Labour Market Policies: A Regional Study of Employer Engagement in the Work Programme. Journal of Social Policy 44(3): 443-62. 
Ingold J and Valizade D (2017) Employers' recruitment of disadvantaged groups: exploring the effect of active labour market programme agencies as labour market intermediaries. Human Resource Management Journal 27(4): 530-547.

Gerfin M and Lechner M (2002) A microeconomic evaluation of the active labour market policy in Switzerland. The Economic Journal 112: 854-893.

Kluve J (2010) The effectiveness of European active labor market programs. Labour Economics 17(6): 904-918.

Köhler PA, Thorén KH and Ulmestig R (2008) Activation Policies in Sweden: Something Old, Something New, Something Borrowed and Something Blue. In; Eichhorst W Kaufmann O, Konle-Seidl R (eds) Bringing the Jobless into Work? Berlin: Springer, pp. 257-296.

Liechti F, Fossati F, Bonoli G and Auer D (2017) The Signalling Value of Labour Market Programmes. European Sociological Review 33(2): 257-274. DOI: 10.1093/esr/jcw061.

Martin JP and Grubb D (2001) What Works and for Whom: A Review of OECD Countries' Experiences with Active Labour Market Policies. IFAU Working Paper 14: 1-55.

Nickson D, Warhurst C, Commander J, Hurrell, SA and Cullen AM (2012) Soft Skills and Employability: Evidence from UK Retail. Economic and Industrial Democracy 33(1): 65-84.

OECD (2015) OECD Employment Outlook 2015, Paris: OECD.

OECD (2017) Public expenditure and participant stocks on LMP Number of participants as a percentage of labour force. Available at: http//:stats.oecd.org, (accessed 10.01.2018).

Phelps ES (1972) The Statistical Theory of Racism and Sexism. The American Economic Review 62 (4): 659-661.

Rivera LA (2011) Ivies, extracurriculars, and exclusion: Elite employers' use of educational credentials. Research in Social Stratification and Mobility 29 (1): 71-90. 
Rooth DO (2012) Obesity, Attractivness, and Differential Treatment in Hiring. The Journal of Human Resources 44(3): 710-735.

Rosenbaum JE (2001) Beyond college for all. Career paths for the forgotten half. New York: Russell Sage Foundation.

Sianesi B (2008) Differential effects of active labour market programs for the unemployed. Labour Economics 15(3): 370-399.

Stryker S (1980). Symbolic Interactionism: A Social Structural Version. Menlo Park, California: Benjamin/Cummings Publishing Company.

Swenson PA (2002) Capitalist against Markets: The Making of Labor Markets and Welfare States in the United States and Sweden. Oxford: Oxford University Press.

van der Aa P and van Berkel R (2014) Innovating Job Activation by Involving Employers. International Social Security Review 67(2): 11-27.

Van Belle E, Caers R, De Couck M, Di Stasio V and Baert S (2018) The Signal of Applying for a Job Under a Vacancy Referral Scheme. GLO Discussion Paper 173: 1-34.

Waldinger RD and Lichter MI (2003) How the Other Half Works: Immigration and the Social Organization of Labor, Berkeley: University of California Press.

Yin R (2003) Case Study Research: Design and Methods. Thousand Oaks: Sage. 


\section{Appendix}

\begin{tabular}{|c|c|c|c|c|c|c|}
\hline Code & Gender & Position & Hiring experience & ALMP experience & Sector & Country \\
\hline Hotel1CH & male & HR manager & $<5$ years & yes, no experience & hotel & Switzerland \\
\hline Hotel2CH & male & manager of a hotel & 5 - 10 years & No & hotel & Switzerland \\
\hline Hotel3CH & female & HR manager & $5-10$ years & yes, has experience & hotel & Switzerland \\
\hline Hotel4CH & male & manager of a hotel & 5 - 10 years & No & hotel & Switzerland \\
\hline Hotel5CH & male & manager of a hotel & $>10$ years & yes, has experience & hotel & Switzerland \\
\hline Hotel6CH & female & HR manager & $<5$ years & yes, has experience & hotel & Switzerland \\
\hline Hotel7CH & female & line manager & 5 - 10 years & No & hotel & Switzerland \\
\hline Hotel8CH & female & HR manager & $5-10$ years & No & hotel & Switzerland \\
\hline Hotel9CH & male & manager of a hotel & $>10$ years & yes, no experience & hotel & Switzerland \\
\hline Retail10CH & female & HR manager & $<5$ years & yes, no experience & retail & Switzerland \\
\hline Retail11CH & Male & HR manager & $>10$ years & yes, has experience & retail & Switzerland \\
\hline Hotel12CH & female & HR manager & $<5$ years & No & hotel & Switzerland \\
\hline Hotel13CH & female & HR manager & 5 - 10 years & No & hotel & Switzerland \\
\hline Hotel13CH & female & line manager & 5 - 10 years & No & hotel & Switzerland \\
\hline Retail14CH & Male & HR manager & $>10$ years & yes, has experience & retail & Switzerland \\
\hline Retail15CH & female & HR manager & 5 - 10 years & yes, no experience & retail & Switzerland \\
\hline Retail16CH & female & HR manager & $>10$ years & yes, has experience & retail & Switzerland \\
\hline Hotel1SWE & male & manager of a hotel & $<5$ years & yes, has experience & hotel & Sweden \\
\hline Hotel2SWE & female & line manager & 5 - 10 years & yes, no experience & hotel & Sweden \\
\hline Hotel3SWE & female & line manager & $5-10$ years & No & hotel & Sweden \\
\hline Hotel4SWE & male & manager of a hotel & $>10$ years & yes, has experience & hotel & Sweden \\
\hline Hotel5SWE & female & manager of a hotel & $>10$ years & yes, has experience & hotel & Sweden \\
\hline Hotel6SWE & male & line manager & $>10$ years & yes, has experience & hotel & Sweden \\
\hline Hotel7SWE & female & manager of a hotel & $>10$ years & yes, has experience & hotel & Sweden \\
\hline Hotel8SWE & female & line manager & 5 - 10 years & yes, has experience & hotel & Sweden \\
\hline Hotel9SWE & female & HR manager & $<5$ years & yes, has experience & hotel & Sweden \\
\hline Hotel10SWE & male & manager of a hotel & $>10$ years & yes, has experience & hotel & Sweden \\
\hline Hotel11SWE & female & manager of a hotel & $<5$ years & yes, no experience & hotel & Sweden \\
\hline Hotel12SWE & male & $\begin{array}{l}\text { manager of a hotel } \\
\text { manager of a }\end{array}$ & $5-10$ years & yes, has experience & hotel & Sweden \\
\hline Retail1SWE & male & supermarket & $>10$ years & yes, has experience & retail & Sweden \\
\hline Retail2SWE & male & line manager & $>10$ years & yes, has experience & retail & Sweden \\
\hline
\end{tabular}




\section{Author biographies}

Flavia Fossati is Assistant Professor for Inequality and Integration Studies at the University of Lausanne (Switzerland). Previously she has been appointed as Assistant Professor for Social Policy at the University of Vienna. She has been a visiting fellow at EUI and at Malmö University. Her research interests include social and immigration policies, and survey experiments. Her research is published, among others, in Cambridge University Press, European Sociological Review and International Migration Review.

Fabienne Liechti holds a PhD in Public Administration from the University of Lausanne. Her research interests include labour market policies and activation, unemployment, and comparative and welfare state research. In her PhD thesis she examined how employers value participation in activation measures when taking hiring decision.

Anna Wilson is a PhD student at Giuliano Bonoli's social policy chair at the Swiss Graduate School of Public Administration (IDHEAP) at the University of Lausanne. Her doctoral studies make part of the Leading House "Governance in Vocational and Professional Education and Training" (GOVPET). Her work is mainly focused on firms' role in including disadvantaged youths in dual vocational education and training systems and how different institutional set-ups might influence their willingness and capacity to do so. 